\title{
M-Learning Pendidikan Karakter untuk Anak Usia Dini Berbasis Augmented Reality
}

\author{
Elsa Patricia Senduk ${ }^{1 *}$, Alicia A. E. Sinsuw ${ }^{2}$, Stanley D. S. Karouw ${ }^{3}$ \\ ${ }^{1,2,3}$ Program Studi Teknik Informatika, Fakultas Teknik, Universitas Sam Ratulangi \\ 120216042@student.unsrat.ac.id ${ }^{1}$, stanley.karouw@unsrat.ac.id ${ }^{2}$, alicia.sinsuw@unsrat.ac.id ${ }^{3}$
}

\begin{abstract}
Abstrak - Peranan teknologi dinilai sangat penting untuk masyarakat umum dalam berbagai bidang tak terkecuali pada bidang pendidikan, perubahan gaya belajar pun mulai mengikuti perkembangan teknologi saat ini. Perkembangan ini membawa pengaruh besar dalam proses belajar mengajar baik di tingkat pendidikan anak usia dini hingga perguruan tinggi, misalnya sekarang ini para pengajar sudah dituntut untuk memberikan materi pelajaran dengan cara yang lebih interaktif dan menarik agar anak didik mudah dalam memahami pelajaran.

Pendidikan karakter merupakan salah satu pelajaran yang termasuk dalam kurikulum pendidikan tingkat anak usia dini atau PAUD. Pelajaran tentang pendidikan karakter, pengajar PAUD sendiri merasa masih sulit untuk mendapatkan alat peraga yang sesuai dengan pelajaran pendidikan karakter. Untuk kasus seperti ini, sebenarnya dengan perkembangan teknologi yang begitu pesat, pengajar tidak harus berpaku pada alat peraga biasa, pengajar bisa menggunakan alat peraga dengan model yang sudah didigitalkan.

Pada saat ini, penelitian yang berjudul "M-Learning Pendidikan Karakter untuk Anak Usia Dini Berbasis Augmented Reality" akan menghasilkan sebuah pengembangan pembuatan konten karakter dengan model animasi 3 Dimensi. Teknologi yang diterapkan pada pengembangan aplikasi ini adalah teknologi augmented reality (AR), teknologi AR ini merupakan penggabungan dunia maya dan dunia nyata yang terjadi secara realtime. Teknologi AR digunakan sebagai visualisasi animasi 3 dimensi tentang pelajaran pendidikan karakter. Aplikasi yang dihasilkan adalah sebuah alat peraga digital atau suatu media belajar yang interaktif dan menarik yang dikhususkan untuk membantu proses belajar mengajar yang dilakukan di tingkat pendidikan anak usia dini.
\end{abstract}

Kata kunci - M-Learning, Alat Peraga, PAUD, Augmented Reality, Android

\section{PENDAHULUAN}

Berdasarkan Undang-Undang Nomor 20 Tahun 2003 tentang sistem pendidikan nasional bab 1 menyatakan bahwa pendidikan anak usia dini adalah suatu upaya pembinaan yang ditujukan kepada anak sejak lahir sampai dengan usia 6 tahun yang dilakukan melalui rangsangan pendidikan untuk membantu pertumbuhan dan perkembangan rohani dan jasmani anak agar anak memiliki kesiapan mental dalam memasuki pendidikan lebih lanjut (UU Nomor 20 Tahun 2003 BAB I Pasal 1 Ayat 14)..

Menurut Kemendiknas (2010) sebagaimana disebutkan dalam buku induk kebijakan Nasional pembangunan karakter bangsa tahun 2010-2025 pembangunan karakter yang merupakan upaya perwujudan amanat Pancasila dan
Pembukaan UUD 1945 dilatarbelakangi oleh realitas permasalahan kebangsaan yang berkembang saat ini, seperti : disorientasi dan belum dihayatinya nilai-nilai pancasila; keterbatasan perangkat kebijakan terpadu dalam mewujudkan nilai-nilai Pancasila; bergesernya nilai etika dalam kehidupan berbangsa dan bernegara; memudarnya kesadaran terhadap nilai-nilai budaya bangsa, ancaman disintegrasi bangsa; dan melemahnya kemandirian bangsa.

Perkembangan teknologi di era globalisasi saat ini menjadi bagian penting dalam kehidupan manusia dan memberikan andil yang besar dalam hal perubahan pada bidang apapun termasuk bidang pendidikan. Perubahan yang dimaksud ialah dapat dimanfaatkan sebagai media belajar dalam proses belajar mengajar, mulai dari pendidikan tingkatan anak usia dini hingga perguruan tinggi.Mobile Learning dapat diartikan sebagai perpotongan komputasi mobile dan e-learning dimana sumber daya harus dapat di akses di manapun, kaya interaksi, dukungan yang kuat untuk pembelajaran efektif, dan penilaian berbasis kinerja.

Teknologi mobile learning (M-Learning) yang dikhususkan untuk para pengajar yang membutuhkan sentuhan teknologi ketika melakukan aktivitas mengajar. Pengajar di tingkatan apapun sekarang ini dituntut untuk semakin kreatif pada saat melakukan proses belajar mengajar, pada kali ini teknologi yang akan dibuat peneliti bermaksud untuk membantu pengajar di tingkatan pendidikan anak usia dini agar bisa memanfaatkan teknologi sebagai alat peraga yang menarik, sehingga melalui media belajar yang disajikan diharapkan dapat menarik perhatian anak-anak untuk memperhatikan pelajaran tentang pendidikan karakter kristen.

Augmented Reality (AR) merupakan teknologi yang memungkinkan pengguna melihat gabungan benda nyata dan maya di lingkungan yang nyata dan berjalan pada waktu yang nyata. AR dapat juga didefinisikan sebagai teknologi yang mampu menggabungkan objek maya dalam dua dimensi (2D) atau tiga dimensi (3D) ke dalam sebuah lingkungan nyata, kemudian memproyeksikan objek-objek tersebut secara real time.

Penggunaan teknologi AR dalam proses pengembangan aplikasi m-learning, dimaksudkan bahwa teknologi ini dapat menjadi alat peraga digital yang menampilkan tentang pendidikan karaker, yang membuat teknologi ini menarik dan mudah dipahami adalah pelajaran pendidikan karakter akan disajikan dengan animasi bentuk tiga dimensi. Aplikasi akan diberikan kepada para pengajar PAUD, sehingga mereka mendapatkan sebuah media belajar yang didalamnya berisi mengenai pendidikan karakter Kristen yang sebaiknya 
E-Journal Teknik Informatika Vol.9 No 1 (2016), ISSN: 2301-8364

diketahui oleh anak sejak usia dini. Penelitian kali ini dibatasi sampai pada bagian pembuatan konten yang merupakan animasi karakter 3D tentang pendidikan karakter kristen.

\section{LANDASAN TEORI}

\section{A. Pengertian Pendidikan Anak Usia Dini}

Mobile Learning dapat Anak Usia dini merupakan periode awal yang paling penting dan mendasar di sepanjang rentang pertumbuhan dan perkembangan kehidupan manusia. Pada masa ini ditandai oleh berbagai periode penting yang fundamen dalam kehidupan anak selanjutnya sampai periode akhir perkembangannya. Salah satu periode yang menjadi penciri masa usia dini adalah the golden ages atau periode keemasan. Banyak konsep dan fakta yang ditemukan memberikan penjelasan periode keemasan pada masa usia dini, dimana semua potensi anak berkembang paling cepat. (Trianto, 2011).

Menurut Kemendiknas (2010) sebagaimana disebutkan dalam buku induk kebijakan Nasional pembangunan karakter bangsa tahun 2010-2025 pembangunan karakter yang merupakan upaya perwujudan amanat Pancasila dan Pembukaan UUD 1945 dilatarbelakangi oleh realitas permasalahan kebangsaan yang berkembang saat ini, seperti : disorientasi dan belum dihayatinya nilai-nilai pancasila; keterbatasan perangkat kebijakan terpadu dalam mewujudkan nilai-nilai Pancasila; bergesernya nilai etika dalam kehidupan berbangsa dan bernegara; memudarnya kesadaran terhadap nilai-nilai budaya bangsa, ancaman disintegrasi bangsa; dan melemahnya kemandirian bangsa (Gunawan, H., 2012).

Gambar 1 merupakan contoh karakter anak yang menjadi landasan peneliti untuk mengambil 5 karaker yang paling banyak dipilih oleh pengajar dan orangtua murid. Karakter anak pada gambar 1 didapat dari PAUD Farley Christian Children Center.

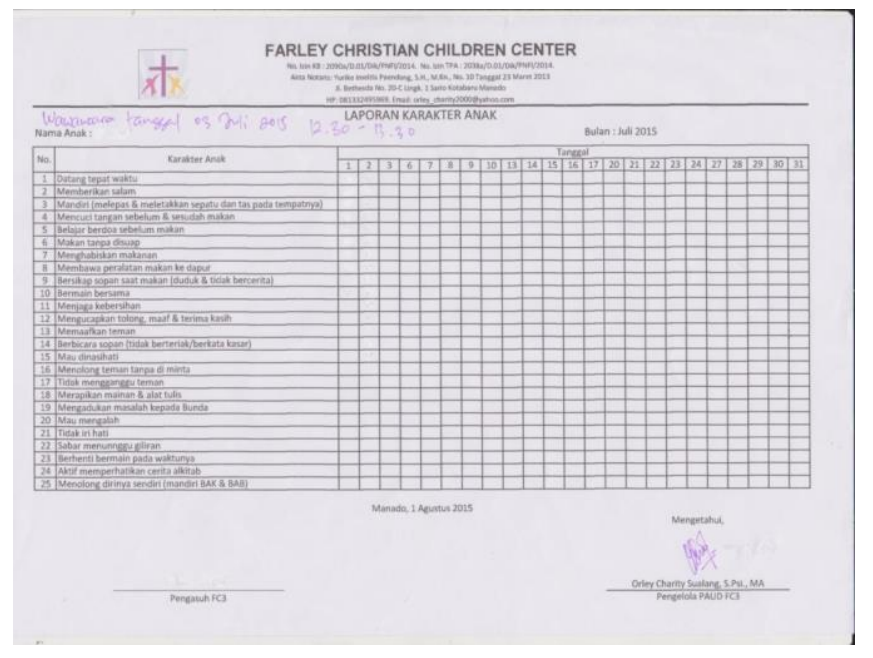

Gambar 1. Karakter Anak Menurut PAUD FC3 Farley Christian Children Center

\section{B. Pengertian Pembelajaran PAUD}

Pembelajaran bagi anak usia dini pada hakikatnya adalah permainan, bahwa bermain adalah belajar, di mana bermain adalah sebuah kegiatan yang dilakukan berulang-ulang dan menimbulkan rasa senang dan puas bagi anak, bermain sebagai sarana bersosialisasi mendapatkan kesempatan untuk bereksplorasi, mengekspresikan perasaan, berkreasi, dan menemukan sarana pembelajaran yang menyenangkan, sekaligus sebagai wahana pengenalan diri dan lingkungan sekitar anak mendapati kehidupannya.

Materi pembelajaran PAUD juga amat variatif. Ada pendapat yang menyatakan bahwa PAUD hanya mengembangkan logika berpikir, berperilaku, dan berkreasi. Ada pula yang menyatakan bahwa PAUD juga mempersiapkan anak untuk siap belajar (ready to learn), yaitu siap belajar berhitung, membaca, dan menulis. Ada pula yang menyatakan bahwa materi pembelajaran bebas, yang penting PAUD mengembangkan aspek moral agama, emosional, social, fisik, motorik, kemampuan berbahasa, seni dan intelektual. (Gunawan, H., 2012).

\section{Pengertian Mobile Learning}

(Quinn, 2000) The intersection of mobile computing and elearning: accessible resources wherever you are, strong search capabilities, rich interaction, powerful support for effective learning, and performance-based assessment. ELearning independent of location in time or space. Berdasarkan definisi yang dipaparkan oleh Quinn, dapat dikatakan bahwa mobile learning merupakan kombinasi antara E-Learning dan Mobile Computing yang dapat mengkases suatu aplikasi pembelajaran dengan mudah. Proses pembelajaran dengan mobile learning memanfaatkan teknologi informasi, dimana materi pembelajaran dapat diakses dimana saja dan kapan saja. Manfaat yang didapat dari pembelajaran dengan model mobile learning adalah ketersediaan materi ajar yang lebih menarik untuk disajikan.

\section{Pengertian Augmented Reality}

Augmented Reality merupakan teknologi yang memungkinkan pengguna melihat gabungan benda nyata dan maya di lingkungan yang nyata yang berjalan secara real time atau pada waktu yang nyata. Augmented Reality atau realitas tertambah merupakan suatu teknologi baru dalam bidang multimedia yang dapat menggabungkan dunia nyata dan dunia maya. Augmented Reality dibuat dengan menggunakan komputer yang melakukan generate secara otomatis objek virtual, kemudian menampilkan objek maya tersebut dan sebagai wadah agar objek tersebut terlihat seperti nyata dan real-time terdapat marker. Marker sendiri merupakan kertas dengan memiliki pola yang digunakan untuk melakukan generate objek virtual sehingga dapat ditampilkan secara otomatis dan secara real-time.

\section{METODOLOGI PENELITIAN}

\section{A. Identifikasi Masalah}

Identifikasi masalah dari hasil observasi di PAUD FC3 Farley Christian Children Center:

Bagaimana membuat konten yang menarik dengan memanfaatkan teknologi augmented reality untuk anak usia dini tentang pelajaran pendidikan karakter Kristen? 
E-Journal Teknik Informatika Vol.9 No 1 (2016), ISSN: 2301-8364

\section{B. Pengumpulan Data}

Metode pengumpulan data yang digunakan peneliti pada penelitian ini terdiri dari :

1. Studi Literatur

Pengumpulan data dengan cara mengumpulkan bacaanbacaan yang berkaitan dengan judul penelitian.

2. Observasi

Observasi dilakukan dengan turun langsung ke PAUD Farley Christian Children Center untuk mengetahui kurikulum pembelajaran tentang pendidikan karakter Kristen.

3. Kuisioner

Kuisioner disebarkan kepada 30 orang yang terdiri dari orangtua murid dan pengajar PAUD.

C. Tahapan Pembuatan Konten

1. Melakukan import package vuforia

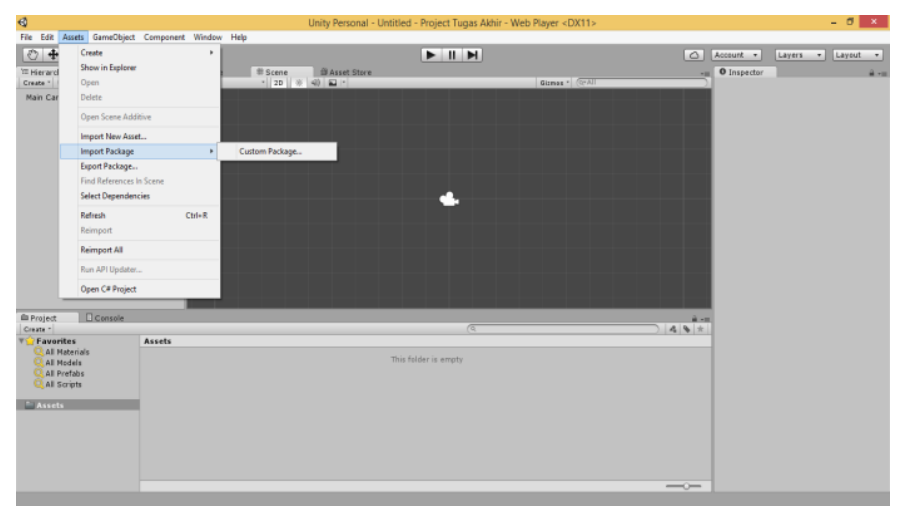

2. Memilih package vuforia

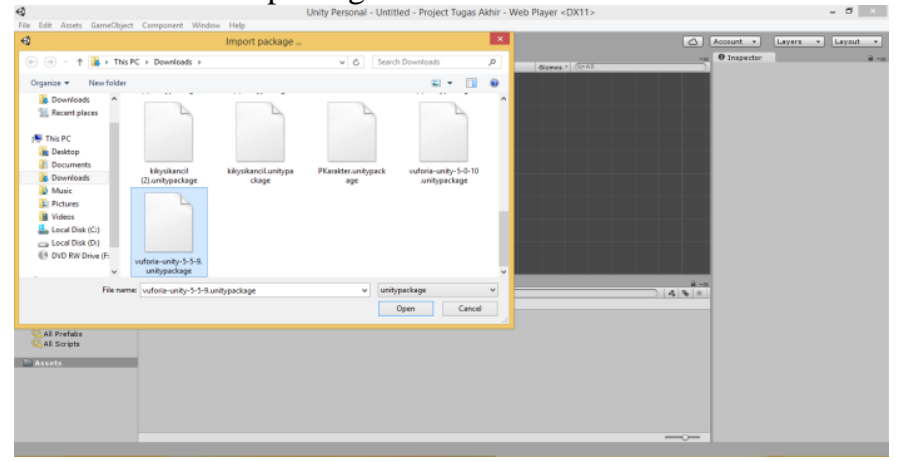

3. Membuat dan Import Database Image Target

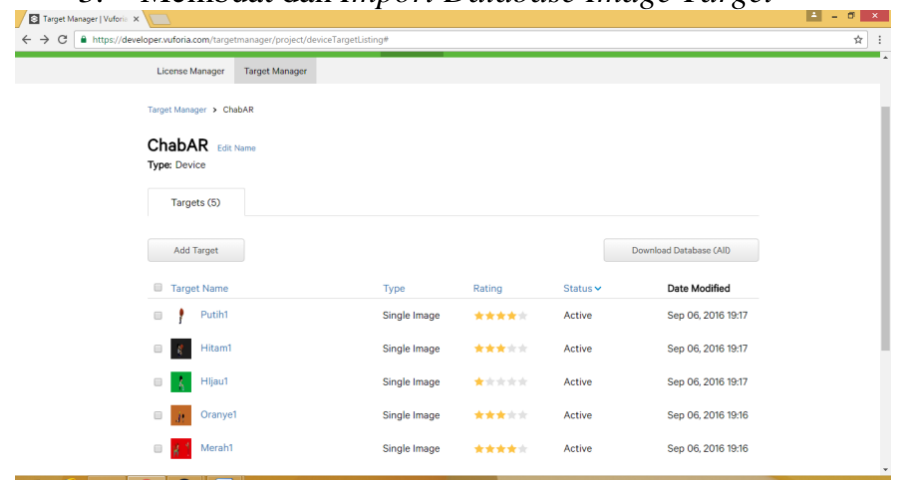

Tahapan nomor 3 merupakan database dari image target yang telah dimasukkan sebelumnya pada web resmi vuforia. www.vuforia.com. Selanjutnya setelah database telah siap, database akan di-import ke unity.
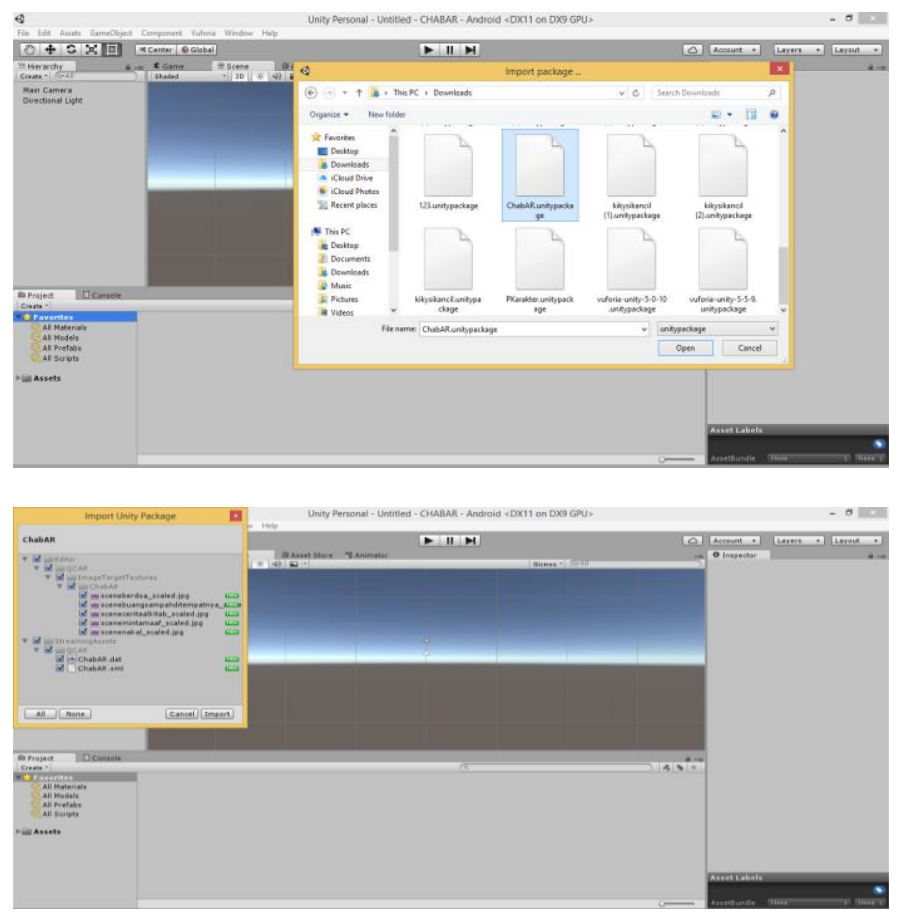

4. Mengatur Kamera AR dan melakukan Load Database Behaviour

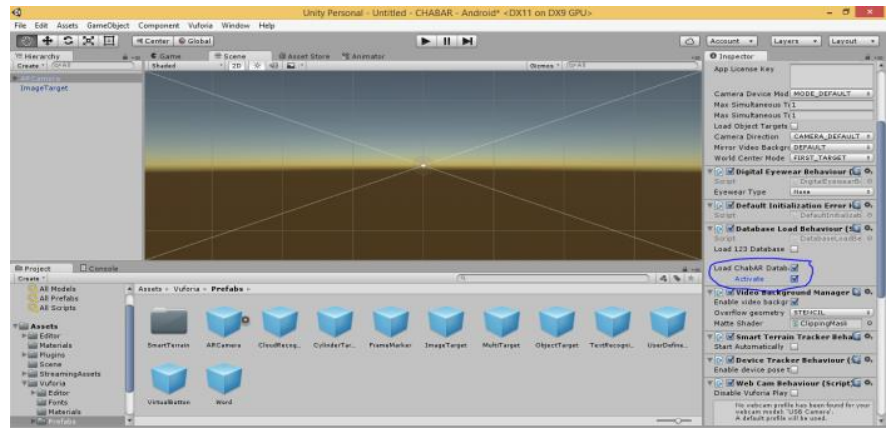

Maksud dari load database adalah ketika semua konten siap di masukkan, database yang telah di-import sebelumnya dapat digunakan sebagai image target untuk teknologi augmented reality Tahapan selanjutnya setelah konten/animasi karakter 3D telah disiapkan, konten siap untuk dimasukkan pada software unity.

\section{Melakukan import konten}

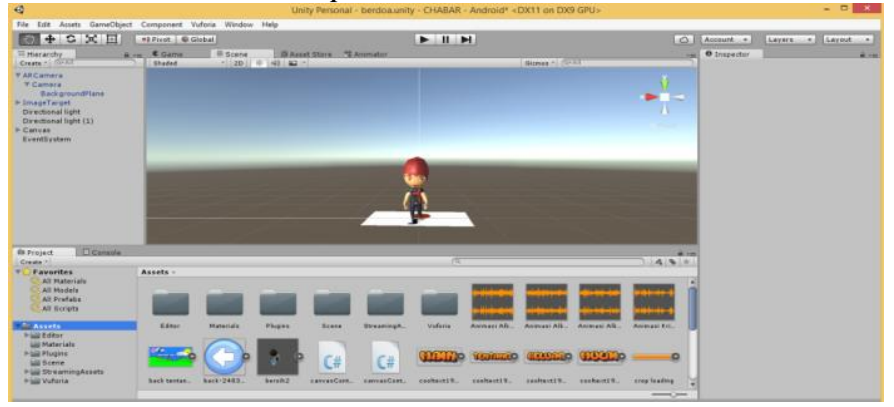


E-Journal Teknik Informatika Vol.9 No 1 (2016), ISSN: 2301-8364
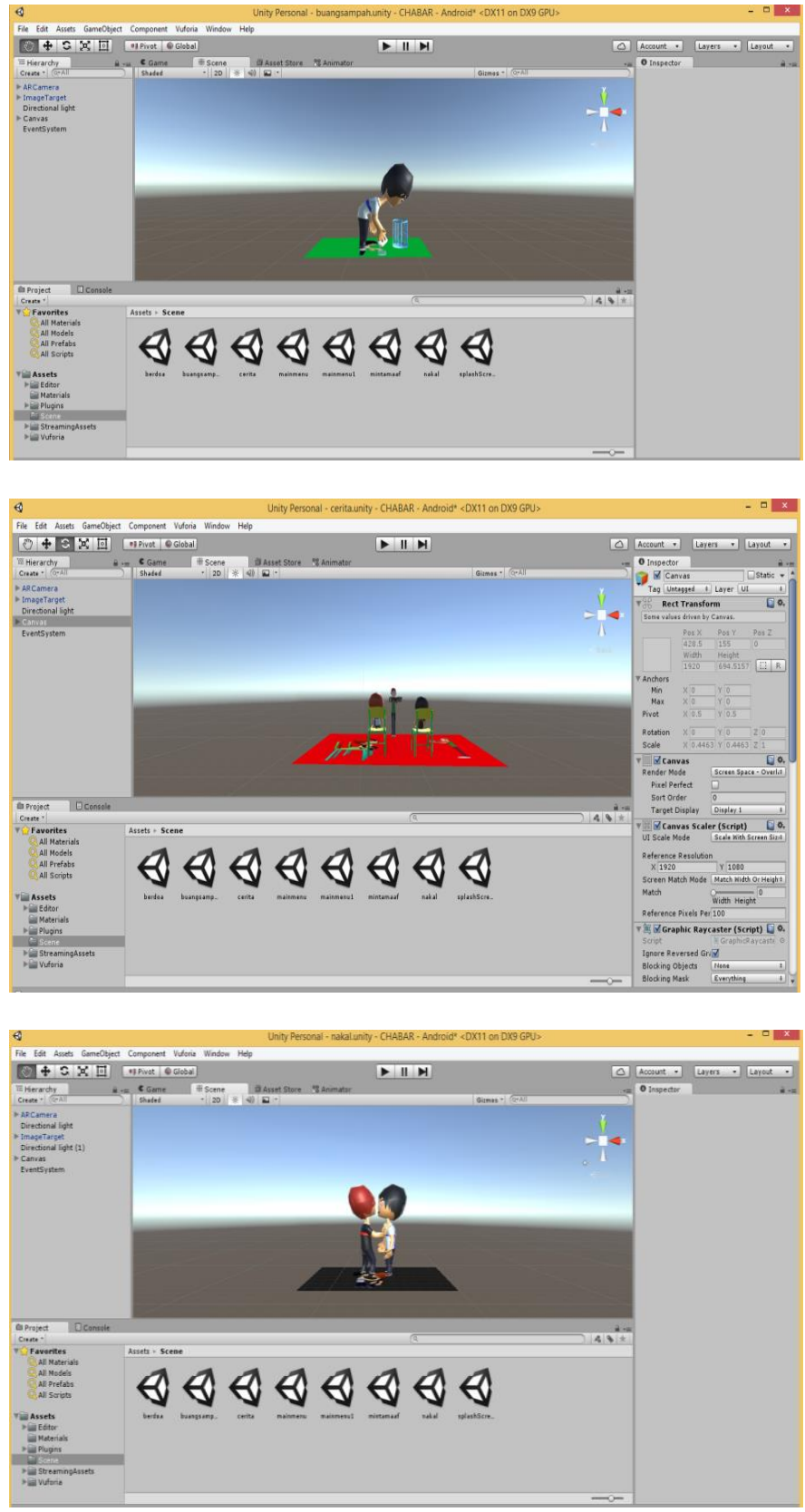

6. Memasukkan Kode License Key

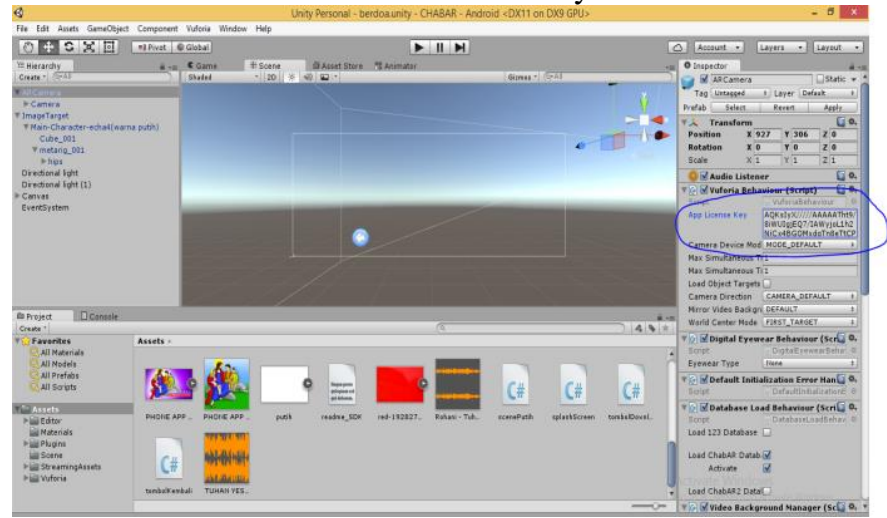

Kode license key digunakan untuk menampilkan konten karakter dengan teknologi augmented reality.
IV. HASIL DAN PEMBAHASAN

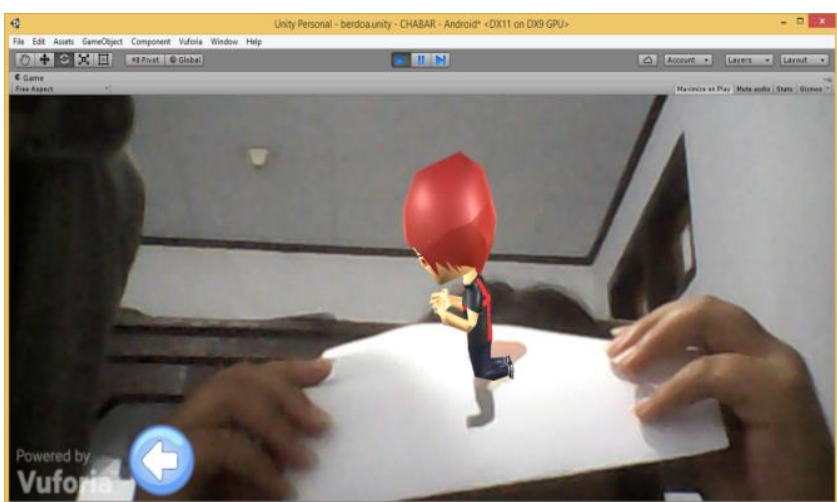

Gambar 2. Tampilan Konten Karakter Berdoa dengan Teknolog Augmented Reality

Tampilan pada gambar 2 merupakan tampilan dari hasil scan image target. Hasil yang ditampilkan merupakan konten karakter 3D dengan teknologi augmented reality.

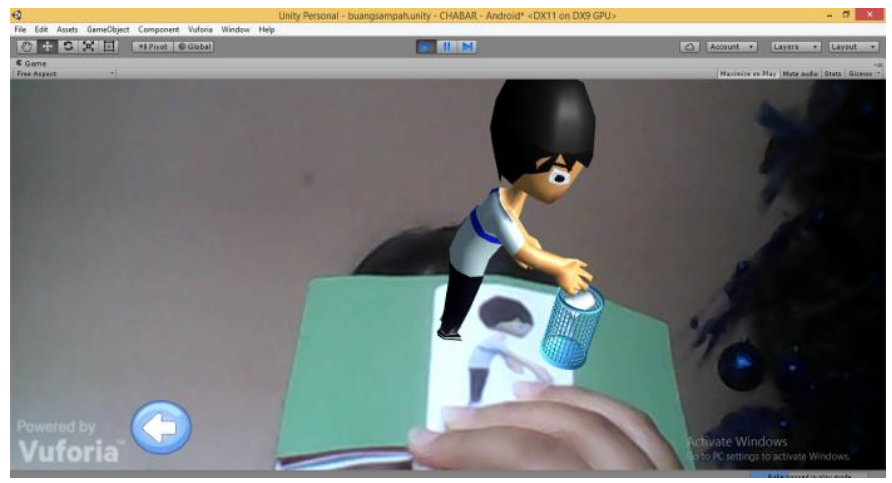

Gambar 3. Tampilan Konten Karakter Buang Sampah dengan Teknologi Augmented Reality

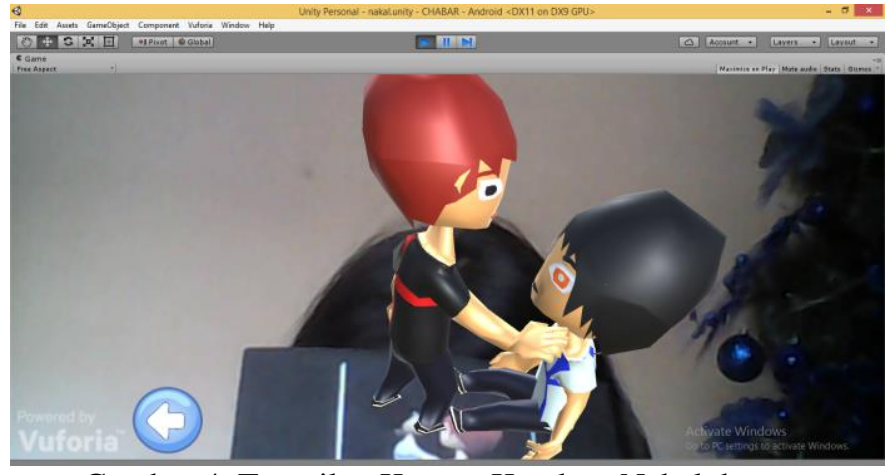

Gambar 4. Tampilan Konten Karakter Nakal dengan Teknologi Augmented Reality

Tabel Penjelasan Konten

\begin{tabular}{|c|c|c|l|}
\hline No. & Warna & Karakter & \multicolumn{2}{|c|}{ Cerita } \\
\hline 1. & Putih & $\begin{array}{c}\text { Anak Laki- } \\
\text { laki }\end{array}$ & $\begin{array}{l}\text { Seorang anak yang } \\
\text { sedang berdoa, } \\
\text { melipat tangan, dan }\end{array}$ \\
\hline
\end{tabular}


E-Journal Teknik Informatika Vol.9 No 1 (2016), ISSN: 2301-8364

\begin{tabular}{|c|c|c|c|}
\hline & & & berlutut. \\
\hline 2. & Hijau & $\begin{array}{c}\text { Anak Laki- } \\
\text { laki }\end{array}$ & $\begin{array}{lll}\text { Seorang } & \text { anak yang } \\
\text { sedang } & \text { membuang } \\
\text { sampah di tempat } \\
\text { sampah } & & \end{array}$ \\
\hline 3. & Merah1 & $\begin{array}{l}\text { Guru Laki- } \\
\text { laki dan } 2 \\
\text { Anak Laki- } \\
\text { laki }\end{array}$ & $\begin{array}{l}\text { Seorang guru sedang } \\
\text { membacakan cerita } \\
\text { dan terlihat } 2 \text { anak } \\
\text { laki-laki yang senang } \\
\text { dan menikmati cerita } \\
\text { yang diberikan oleh } \\
\text { guru mereka. }\end{array}$ \\
\hline 4. & Merah2 & $\begin{array}{c}2 \text { Anak Laki- } \\
\text { laki }\end{array}$ & $\begin{array}{l}\text { Seorang anak yang } \\
\text { melihat temannya } \\
\text { sedang kesusahan } \\
\text { yang terjatuh dan } \\
\text { menolong temannya } \\
\text { untuk berdiri }\end{array}$ \\
\hline 5. & Orange & $\begin{array}{l}\text { Guru } \\
\text { Perempuan } \\
\text { dan Anak } \\
\text { Laki-laki }\end{array}$ & $\begin{array}{l}\text { Seorang anak yang } \\
\text { meminta maaf } \\
\text { kepada gurunya. }\end{array}$ \\
\hline 6. & Hitam & $\begin{array}{c}\text { Anak Laki- } \\
\text { laki }\end{array}$ & $\begin{array}{l}\text { Seorang anak yang } \\
\text { melakukan dosa } \\
\text { karena mendorong } \\
\text { temannya hingga } \\
\text { terjatuh. }\end{array}$ \\
\hline
\end{tabular}

\section{PENUTUP}

\section{A. Kesimpulan}

1. Untuk membuat konten dengan model animasi karakter 3D mengenai pelajaran pendidikan karakter kristen.

2. Untuk memenuhi kebutuhan akan penyajian alat peraga digital sebagai media belajar yang dapat membantu proses pembelajaran mengenai pendidikan karakter Kristen di tingkatan pendidikan anak usia dini.

\section{B. Saran}

Untuk mengembangkan aplikasi M-Learning pendidikan karakter untuk anak usia dini berbasis augmented reality agar terlihat lebih baik maka perlu dilakukan pengembangan lebih lanjut, antara lain sebagai berikut :

1. Menambahkan jumlah karakter agar lebih banyak lagi hal yang bisa diajarkan oleh pengajar kepada anak didik.

2. Mengembangkan pembuatan karakter animasi 3D sebagai aplikasi m-learning yang siap pakai agar bisa dijalankan pada platform android atau iOs.

\section{DAFTAR PUSTAKA}

[1] Gunawan. H. (2012). PENDIDIKAN KARAKTER KONSEP DAN IMPLEMENTASI. Bandung. Alfabeta.Nugroho \& Bunafit. (2005). Database Relasional dengan MySQL, Penerbit Andi. Yogyakarta

[2] Quinn, C. (2000). Mlearning, Mobile Wireless in Your Pocket Learning

[3] Ronald T.Azuma : "A Survey of Augmented Reality" Presence : Teleoperators and Virtual Environments, Vol. 6, No. 4, pp. 355-385, Agustus 1997. Tersedia http://www.cs.unc.edu/ azuma/ARpresence.pdf

[4] Triyanto. (2013). DESAIN PENGEMBANGAN PEMBELAJARAN TEMATIK. Kencana Prenada Media Group.

[5] Undang-undang Republik Indonesia Nomor 20 Tahun 2003 Tentang Sistem Pendidikan Nasional. Diakses: "11 Juli 2016". Tersedia: http://sindikker.dikti.go.id/dok/UU/UU20-2003-Sisdiknas.pdf.

\section{TENTANG PENULIS}

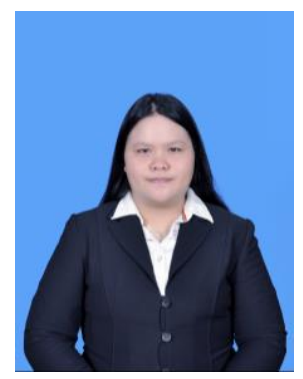

Sekilas dari penulis dengan nama Elsa Patricia Senduk, anak pertama dari dua bersaudara. Lahir di Manado, tanggal 7 Mei 1994. Sekolah pertama tempat belajar adalah SD GMIM 9 Manado. Kemudian melanjutkan pendidikan ke SMP $\mathrm{N} 1$ Manado, dan melanjutkan pendidikan ke SMA N 1 Manado. Pada tahun 2012, Penulis melanjutkan studi di Fakultas Teknik, Jurusan Elektro, Program Studi Informatika, Universitas Sam Ratulangi Manado. Kemudian pada tahun 2015 bulan Agustus penulis membuat skripsi demi memenuhi syarat Sarjana (S1) dengan penelitian berjudul "M-Learning Pendidikan Karakter Untuk Anak Usia Dini Berbasis Augmented Reality Studi Kasus: PAUD Farley Christian Children Center" dengan pembimbing I Alicia A. E. Sinsuw, ST, MTI dan pembimbing II Stanley D. S. Karouw, ST., MTI,. Sehingga pada tanggal 11 November 2016 penulis resmi lulus di Teknik Informatika Universitas Sam Ratulangi dan menyandang gelar sebagai Sarjana Komputer. 